\title{
International Student-oriented Course Construction and Teaching Practice of Engineering Drawing
}

\author{
JIA Hong \\ College of Mechanical Engineering \\ Zhejiang University of Technology \\ Hangzhou 310014, China \\ hjia@zjut.edu.cn \\ SUN Yi \\ Ocean College \\ Zhejiang University of Technology \\ Hangzhou 310014, China
}

\author{
JIN Xiaohang \\ College of Mechanical Engineering \\ Zhejiang University of Technology \\ Hangzhou 310014, China
}

$\mathrm{Hu}$ Xiaxia

College of Mechanical Engineering Zhejiang University of Technology

Hangzhou 310014, China

\author{
BAO Yumei \\ College of Mechanical Engineering \\ Zhejiang University of Technology \\ Hangzhou 310014, China
}

\begin{abstract}
As globalization of higher education goes forward, there's urgent requirement for full English teaching for related majors and curriculum in universities in China. In order to meet the demand, course reform and exploration work has been carried out for the compulsory course "Engineering Drawing" in higher engineering education. This paper first introduces the current status of teacher and international students. Then approaches for course construction are presented based on analysis of student's education and language background. After that, methods for classroom teaching, practice section and course assessment are designed and described in detail. The implementation and feedback of teaching activities in the past few years have confirmed the feasibility and applicability of the course "Engineering Drawing" for international students. At the end suggestions on future curriculum reform are put forward according to the experiences and lessons learned.
\end{abstract}

Keywords-Engineering Drawing; Teaching in English; International Education; Higher Education

\section{INTRODUCTION}

In recent years, with the advancement of internationalization strategy of higher education, more and more colleges and universities have set up English teaching majors for international students. And broad masses of educators have carried on the thorough discussion to foreign student education $[1,2]$, meanwhile university teachers actively carry on the related construction and reform of curriculums taught in English [3-6].
International development strategy is one of the three longterm development strategies of Zhejiang University of Technology (hereinafter referred to as ZJUT). With the advancement of the international development strategy of ZJUT, the number of international student has increased greatly. At present, there are over 1,000 international students studying in the university, and the major covers engineering, economics, science, art, management etc., the level of degree includes undergraduate, master and doctor degree.

"Engineering Drawing" is the basic technical course to all students in engineering fields, the goal of the course is to cultivate students' spatial thinking ability, drawing and reading engineering drawings ability, and to enhance students' engineering practice ability and innovation consciousness. This course aims to lay a solid engineering foundation for further curriculum design and graduation design.

At present, "Engineering Drawing" is a compulsory course to international students majored in all engineering fields. Although "engineering drawing" has a long teaching history in ZJUT, but the course which is taught in English is quite new and facing great challenging. This paper first analyzes the construction and teaching practice of course which students mainly from Asia and Africa. By analyzing the present situation and teaching mode of engineering drawings in English for foreign students, the paper summed up the experiences and lessons, and at the end it put forward some recommendations and suggestions to curriculum construction and reform of the course.

Sponsor: 2016 Classroom teaching reform project KG201607 Zhejiang University of Technology. 


\section{PReSENT Situation OF TEACHING ENGINEERING DRAWING FOR INTERNATIONAL STUDENTS}

\section{A. Teacher's Development}

Teacher is the prerequisite and foundation for the construction and teaching practice of the course "Engineering Drawing" for international students. Based on Zhejiang province excellent course "Engineering Drawing" teaching team, teachers with oversea studying or working experience were selected to participate in the team for "Engineering Drawing" which taught for international students in English. Meanwhile, teachers who has both good English language skills and course teaching experiences are also welcomed to join the team. Currently, there're 5 teachers in the team, 3 of them hold the oversea degree and 4 of them have oversea working experiences.

On the other hand, favorable policy and strong support from ZJUT are provided for teacher's development and course construction. Following lists some of them,

- Special fund is set up for teacher's oversea training programs.

- English language training program is given by the College of Foreign Language.

- Teacher Development Center holds seminar for experts and scholars from home and abroad to share and exchange teaching methods and experiences in particular fields.

By various measures, teaching ability for this course in English will be gradually improved, and it ensures the implementation of the course taught in English for international students.

\section{B. Status of International Students}

Students, as an important participant in teaching process, is a vital factor which not only influences the teaching process but also helps to reach good teaching results. Since international students are from different countries or regions in the world, a more comprehensive understanding of students' language, education and cultural background, finding out students' learning objectives will do benefit to the implementation of the teaching process, and achieve curriculum purpose.

At present, course "Engineering Drawing" involves the international students major in mechanical, chemical, environmental, materials, computer, information and other engineering fields. By doing survey of the international students who took the course, following characteristics are summarized:

- Language background: International students mainly from Middle East and Africa, a few from Southeast Asia. Students' mother languages include English, French, Arabic, Russian, with various accents. Take the mechanical engineering 2016 as an example, the total number of student is 25 , among those 6 students are using English as the official language, 1 student took TOEFL test, 1 student took HSK, as shown in
Fig.1. Most of the students are able to communicate in English while a small amount of students have difficulties in understanding both English and Chinese. For those students, methods like electronic dictionaries, translation from their native language speaking classmate, etc. are used to help them better understand the course.

- Educational background: Most of the students come from developing countries, and there's no entrance academic examination requirement for them. Under such situation, there exists a large gap of the knowledge structure and ability level among those foreign students. So during teaching process, teachers need to design new teaching content and adjust teaching method according to the specific situation of students.

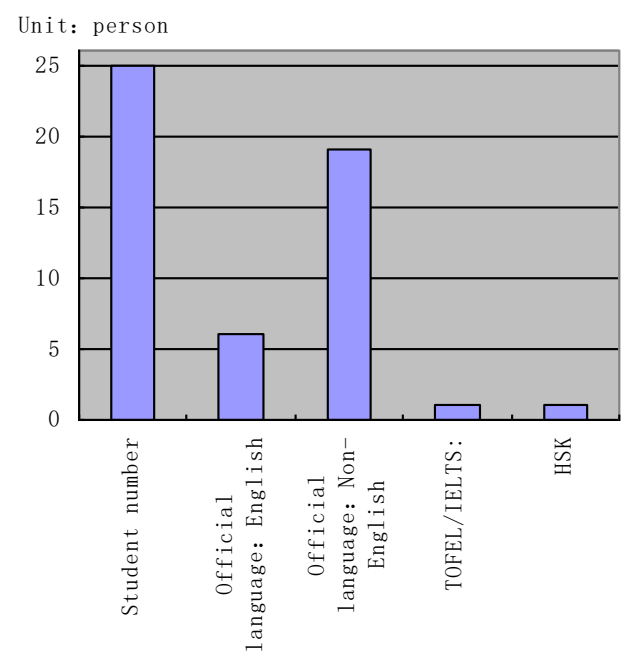

Fig. 1 Analysis on language background of international student

- It's quite common that students are late, absent for class, and those will seriously affect the teaching process and result in negative course results.

- As for interactivity in class, international students are more active comparing with Chinese student.

\section{TEACHING MODEL OF ENGINEERING DRAWING FOR INTERNATIONAL STUDENTS}

Taking industrial product drawings as research object, Engineering Drawing mainly focuses on the graphical representation, digital graphics information generation and graphics information transfer [7]. The course aims to equip students with following ability: (1) Able to understand the basic principle of orthographic projection and its applications; (2) Able to use two-dimensional drawings to express threedimensional model; (3) Ability for spatial imagination; (4) Able to do creative design; (5) Able to do free hand drawing and ruler drawing; (6) Able to read and draw professional engineering drawings; (7) Develop basic awareness of 
engineering, standardization and regulations. In order to achieve the above course objectives, research and reform considering the classroom teaching, practice and curriculum assessment have been implemented, and will be illustrated in the following section.

\section{A. Classroom Teaching}

Considering the language background, knowledge level and acceptability of international students, we have adjusted and reorganized the content, level, depth and breadth of the "Engineering Drawing" course. Through years of "Engineering Drawing" teaching practices, the full English multimedia courseware of "Engineering Drawing" has been completed. To help student pre-class preview and after-school review, not only bilingual teaching materials but also multimedia courseware are recommended to students.

Course "Engineering Drawing" for international students are taught in English, it uses a combination of multimedia and blackboard (blackboard hand drawing).

For new terms, standards, norms and definitions, power point is used to ensure that students could obtain information efficiently; and for product modeling and graphics generation, freehand drawing on blackboard is applied: This approach reflects teacher's thinking process more clearly meanwhile teacher could also adjust the speed according to the feedback of students to make the classroom more interactive, leaving more time for students to think, and better understand the modeling process, such that students cognitive process could catch up with teacher's explaining speed. By doing so, the performance in the classroom could be improved.

According to the ease level and importance of teaching content, the synchronization practice will be applied to help students better understand the knowledge. Fig.2. shows the students on the blackboard to solve problem. Setting up this section in class, on the one hand, is to attract students' attention in class, to promote their active thinking, to ensure students could keep up with the teaching process; on the other hand, through hands-on exercises, it's easier to find a common problem among students which more efforts may be needed to solve problem.
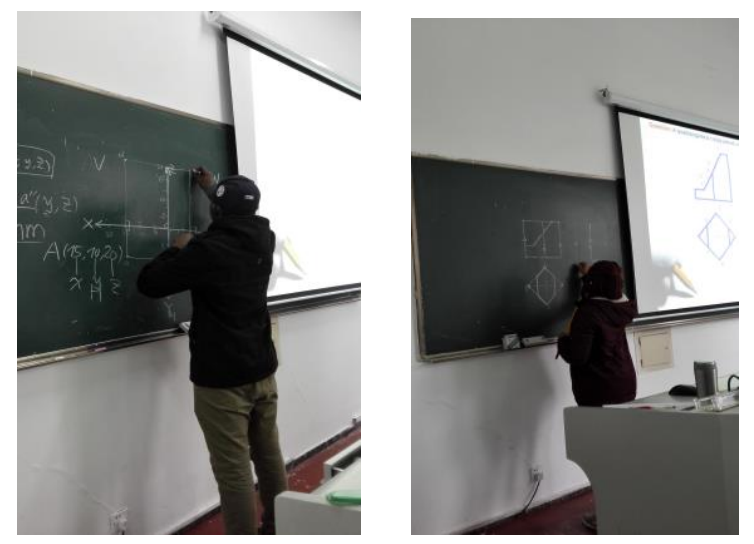

Fig. 2 Students do practice in class
Appropriate learning methods are provided to students. It's highly suggested that carefully review the contents of the previous lesson before class will lay the foundation for better understanding new knowledge. Wood mold, three-dimensional model and other auxiliary means are widely used to help students understand the knowledge. Fig.3. is the student's homework, a question with multiple solutions.
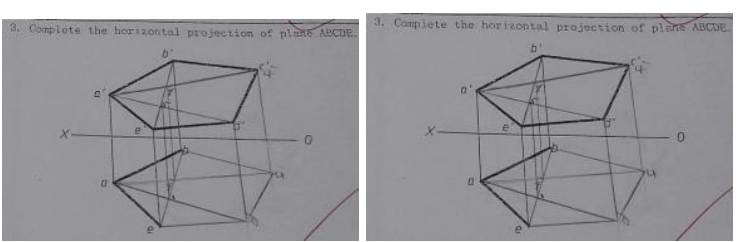

Fig. 3 Examples of students' homework

\section{B. Practice Section}

In order to better achieve the goal of engineering drawing, mechanical parts surveying and mapping has been set up as practical section. Through the practice, students could apply the theory into practice, improve the basic drawing skill, better understand national standards, and lay a solid foundation for subsequent courses. Fig.4. shows the students' drawings of mechanical parts surveying and mapping. Through practical section, students develop following abilities:(1) Get familiar with the usage of drawing tools, develop the correct drawing methods and skills; (2) Have better understanding of the expression of mechanical parts, dimension, standard parts; (3) Develop the ability to observe, analysis and solve problem; (4) During surveying and mapping, students also put forward problems considering design issues which lay the groundwork for subsequent courses.
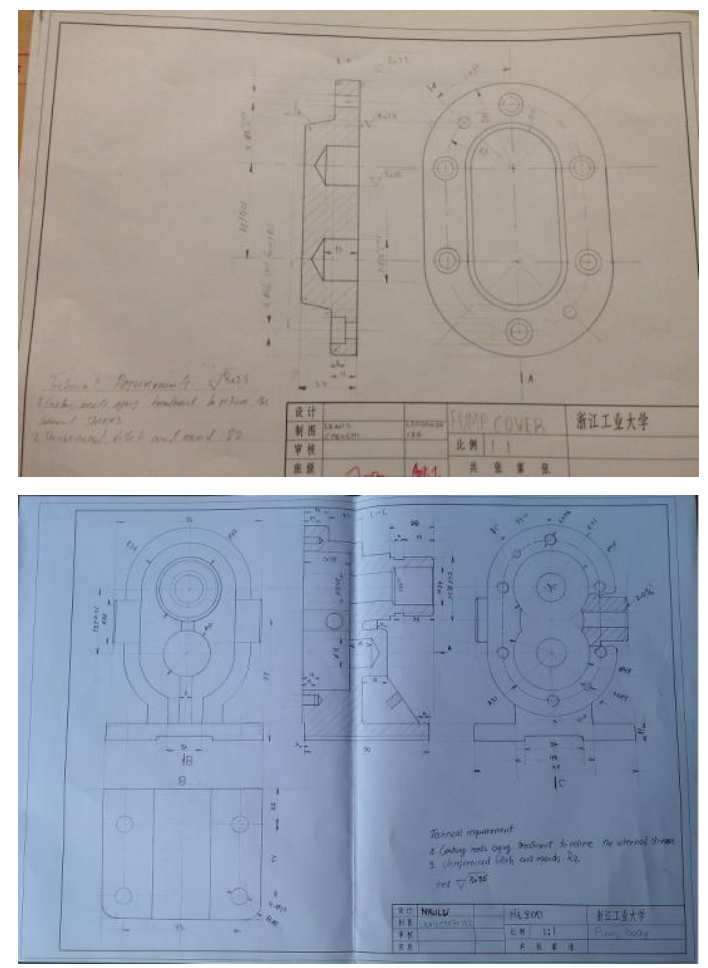

Fig. 4 Examples of students' drawing 


\section{Course Assessment}

Consider the differences of students' educational and language background, course assessment pay more attention to students' learning process. The commonly used final examination method was modified, a comprehensive assessment system is applied as following:

- Attendance system: $15 \%$. Sign for attendance sheet.

- Quiz in class: 5\%. It takes 5-10 minutes to do quiz in class from time to time. By so doing, attendance punctuality could be promoted and students could put effort in reviewing and preparation work.

- Bonus point: $5 \%$. Students are given the opportunity to do exercises on blackboard. It helps to enhance the student's attention in class.

- After class assignment: 15\%. Exercise paper is provided for students to practice after class. It helps to consolidate and expand the understanding of knowledge.

- Mid-term examination: $10 \%$. Complete mid-term exam paper in a given time.

- Final exam: 50\%. Complete final exam paper in a given time.

We hope that above-mentioned comprehensive assessment methods could help to promote students to participate in the entire teaching process, to guide them active learning and to ensure the smooth and orderly implementation of the teaching process.

\section{CONCLUSION}

Internationalization of higher education is an important way to improve the quality of higher education, and it's also the basic trend of higher education reform and development. Under this context, ZJUT has implemented curriculum reform in internationalization construction of mechanical engineering, chemical engineering and other engineering majors.

This paper mainly summarized the curriculum construction and teaching implementation, and introduced in detail the principles, the teaching methods and the concrete teaching methods adopted in the curriculum construction and implementation process. The implementation and feedback of the teaching activities in the past few years have confirmed the feasibility and applicability of the course "Engineering Drawing" for international students. At the same time, the experience and lessons learned from the teaching practice in the past few years have put forward a new direction for the reform and practice of the English course "Engineering Drawing": (1) Improve construction of teaching resources. (2) Establish teaching assistant system: hire graduate student as course tutor. (3) Apply Chinese-International students mixed class system: on one hand Chinese student could improve their English communication ability, on the other hand, international students can learn from Chinese students. Win-win situation could be reached at the end.

\section{ACKNOWLEDGMENT}

We gratefully recognize Zhejiang University of Technology for funding this research.

\section{REFERENCES}

[1] Q.L. Cui, "Problems in China' S Education for Overseas Students and their Causes", Education and Modernization, China, 2008(3), pp.7480.(In Chinese)

[2] B.L. Wang, "Analysis on the Characteristics of Education for Overseas Students in China and Its Development Opportunity", The Science Education Article Cultures, China, 2013(4), pp.36-37. (In Chinese)

[3] K.J. Zhu, S.S. Liu, J.N. Ding, etc. "The Practice and Enlightenment of Short Course of Technical Drawing \& CAD by American Professor", Journal of graphics, China, 2015, 36(2), pp. 622-625. (In Chinese)

[4] J. Feng, "Analysis on Engineering Graphics Education in U. S. Universities", Journal of engineering graphics, China, 2008(3), pp. 139-144. (In Chinese)

[5] W.W. Mao, "Studying on the Teaching of Engineering Graphics in University of California, San Diego", Journal of engineering graphics, China, 2007(5), pp. 172-177. (In Chinese)

[6] Y. Liu, K. Li, M. Cao, etc. "The Innovation and Practice of Engineering Drawing Teaching Based on All-Around Opening Labs", Journal of graphics, China, 2017, 38(1), pp. 123-127. (In Chinese)

[7] B.S. Tong, "Cognition to the Discipline of Engineering Graphics and the Discipline of Graphics", Journal of engineering graphics, China, 2010(6), pp.1-6. (In Chinese) 